\title{
Assessing the Influence of Planning on Selected Instructional Behaviours of Physical Education Students from University of Education, Winneba on Internship in the Volta Region of Ghana.
}

\author{
Lawson Gordon Nyavor, Richmond Stephen Sorkpor, Simon Fiadzo \\ Tutor, Akatsi College of Education, Akatsi, Ghana \\ Tutor, OLA College of Education, Cape Coast, Ghana \\ Tutor, Kibi Presbyterian College of Education, Hohoe, Ghana
}

\begin{abstract}
The purpose of this study was to assess the influence planning have on selected instructional behaviours of a group of student-interns across two teaching conditions, one planned and one unplanned. Eight physical education student-interns from the Department of health, Physical education, Recreation and Sports of University of Education, Winneba taught two 30-minute lessons to Senior High School and College of Education students. Lesson plans were developed for the first lesson (planned condition) but not the second (unplanned condition). All lessons were videotaped and employed in the data analyses. Three data collection instruments were used for the analysis of selected teaching behaviours: (a) an event recording instrument for coding teacher verbal feedback statements, (b) the Qualitative Dimensions of Lesson Introduction, Task Presentation, and Lesson Closure (QDITC) system and an interview. The results suggest that planning has a positive influence on student-interns' instructional behaviours. For teachers in training, it seems that planning is important to the employment of "effective" teaching behaviours in the interactive teaching environment.
\end{abstract}

Keywords: Student-Interns, teaching environment, planning, instruction

\section{Introduction}

Fundamental to the role of a teacher is the capacity to identify and plan quality instructional programmes. Planning refers to that domain of teaching in which teachers formulate a course of action for carrying out instruction over a school year, semester, week, day, or lesson. Probably the most widely accepted idea in education is that the value and productivity of a given teaching and learning encounter depends upon thorough and meticulous planning. On the other hand, the notion persists that the absence of planning or haphazard planning leads to a wasteful, unproductive lesson. The assumption, then, is that planning affects in some systematic way the manner in which teachers behave in a classroom or that decisions made by teachers during the planning process have an influence on all aspects of their classroom behaviour (Sherman, 1979).

It follows from this that much of a teacher's behaviour in a classroom should be predictable by examining the teacher's lesson plan for a particular class. Such things as the content to be taught, the materials to be used for instruction, the activities in which the teacher and students will engage, and the way in which the class will be organized are aspects of classroom behaviours that may fairly easily be predicted from a lesson plan. The importance of these aspects of the classroom milieu is undeniable, yet they provide an incomplete picture of the teaching and learning process.

Teaching is an ongoing, interactive, self-adjusting process in which teachers must make instantaneous decisions about how to respond to students and others under constantly changing conditions. It is within the context of these decisions and interactions that the teaching and learning process unfold. Little research has been completed about the effect of planning upon the ongoing, interactive behaviours of 
teachers as they engage their students in the learning process. As a consequence, questions like those posed above continue to go mostly unanswered.

Over the past three decades or so, instructional behaviours have been studied in classroom and gymnasium settings to better understand what make some teachers more effective than others, hence maximizing student achievement. In recent times, the attention has been shifted to studying teachers' planning and teaching behaviours to gain more insight into teacher effectiveness. Planning seems to play a fundamental role in linking curriculum to instruction and, in turn, in influencing what goes on in the interactive teaching environment. Yinger (1979 p.164) suggests that "teacher planning is the major tool by which teachers manipulate the environments that later shape and control their own behaviour" (p.164).

A significant proportion of instruction consists of teachers making decisions and judgments about what their students should learn, are learning, and have learned, and what instructional activities are appropriate. In most Physical Education Teacher Education (PETE) programmes, a considerable amount of time is devoted to the planning process without knowing much about how planning affects the instructional behaviours of teachers in training. If teacher educators are to continue to hold the belief that planning contributes to effective teaching, then there is a need to continue to examine the relationship between planning and instruction more completely.

\section{Statement of the Problem}

It is widely accepted that planning prior to teaching and learning has a significant impact on the effectiveness of teachers but without knowing how much this affects positively teaching and learning and also the specific aspects of instructional behaviours that are affected by planning. The most widely accepted idea in education is that the value and productivity of a given teaching and learning encounter depends upon thorough and meticulous planning. On the other hand, the notion persists that the absence of planning or haphazard planning leads to a wasteful, unproductive lesson. The assumption, then, is that planning affects in some systematic way the manner in which teachers behave in a classroom or that decisions made by teachers during the planning process have an influence on all aspects of their classroom behaviour (Sherman, 1979).

Some of the Students from the University of Education, Winneba, in the department of Physical Education on internship perform very well whiles others put up dismal performances. Most at times reasons why this happens was difficult to come by. It is against this background that the researcher decided to examine the influence of lesson planning on some selected instructional behaviours by comparing planned lessons and unplanned lessons that were taught by internship Physical Education major students from the University of Education, Winneba.

\section{Purpose of the Study}

The purpose of this study was to assess the influence of planning on selected instructional behaviours of a group of internship Physical Education major students who were on their internship programme.

\section{Research Questions}

i. What influence does planning have on the provision of feedback by student interns?

ii. What influence does planning have on accuracy of cues by interns?

iii. How does planning affect demonstration by interns?

iv. How does planning affect clarity of task?

\section{Methodology}

The design used for this study was a mixed methods design in educational research

This approach permits data triangulation. The settings for this study were six (6) selected Senior High Schools and two (2) Colleges of Education in the Volta Region of Ghana where the student-interns were practicing.

The target population for the study was all the student-interns numbering eighty-four (84) from the Department of Health, Physical Education, Recreation and Sports (HPERS), University of Education, Winneba. This number comprised eight (8) females and seventy-six (76) males. Further, all the first year 
Senior High School students that these student-interns were teaching served as the target population for the study.

Purposive and simple random sampling procedures were used in selecting a sample of eight (8) Physical Education student-interns, seven (7) males and one (1) female.

Two instruments were used for data collection and analysis for this research work.

They include:

- A modified version of the task presentation portion of the Qualitative Dimensions of Lesson

Introduction, Task Presentation, and Lesson Closure System (QDITC; Byra 1992).

- An event recording instrument for coding congruent feedback statements.

- Interview.

Face-to-face interviews were performed by taking notes while talking with respondents. The notes were subsequently structured (interpreted) for further analysis

The eight (8) student-interns each taught two 30-minute lessons to the sampled learner subjects. Lesson plans were developed for the first lesson taught (planned condition) but not for the second (unplanned condition.

All of the planned and unplanned lessons were videotaped. A wireless microphone was worn by the trained research assistants to allow for accurate coding of verbal feedback. The videotapes were employed in the data analyses.

\section{Results/Discussion}

\section{Research Question1: What influence does planning have on the provision of feedback of interns?}

The purpose of this question was to assess the influence of planning on the provision of feedback by student interns. In answering this research question, the question on congruent feedback was used to elicit data from the interns and is presented below.

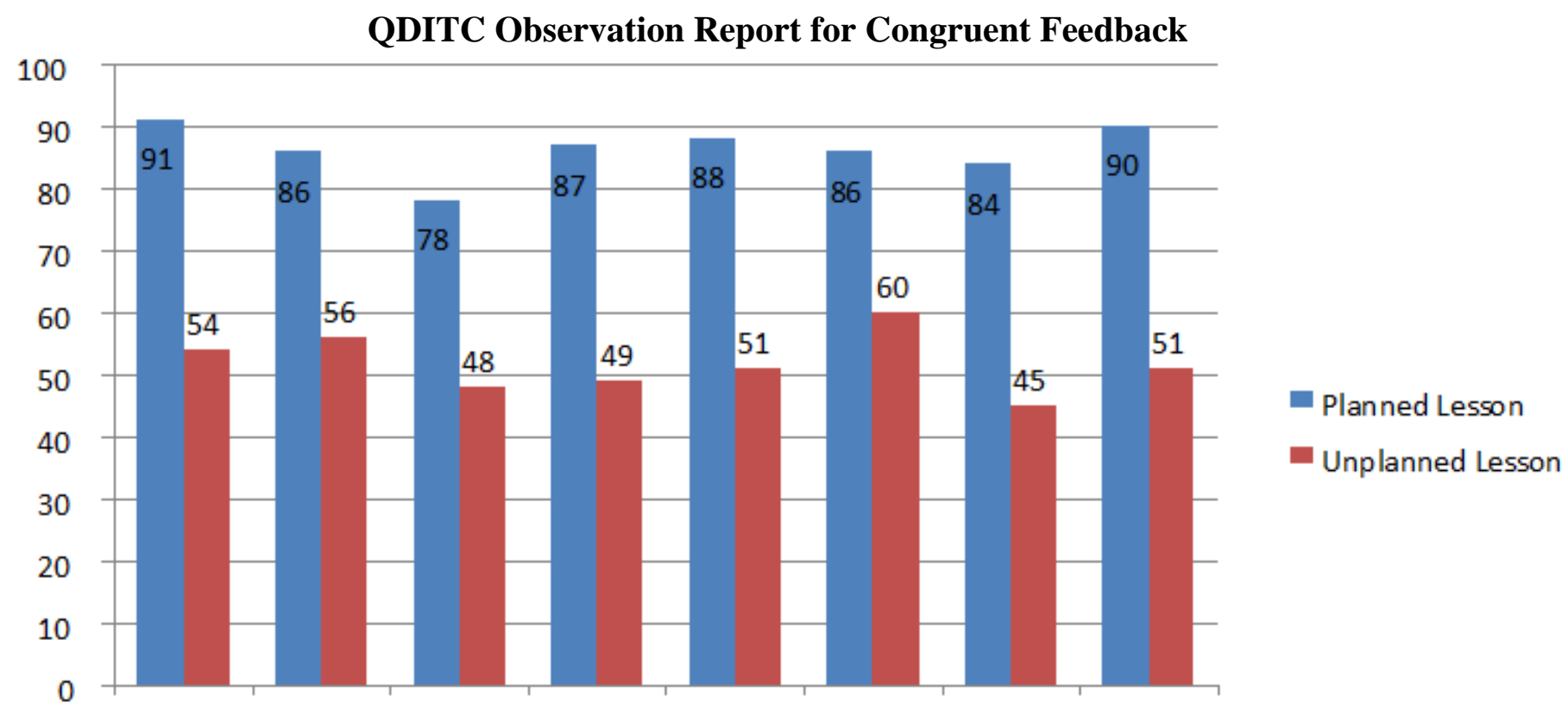

Intern 1 Intern 2 Intern 3 Intern 4 Intern 5 Intern 6 Intern 7 Intern 8 Figure 1: QDITC Observation Report for Congruent Feedback

Figure 1 presents the individual scores of intern teachers on the QDITC instrument for planned and unplanned lessons. The table presents the average total percentage score for the observed lessons. There is clearly an observed difference between the planned lessons and the unplanned lessons. The average percentage score for feedback for the planned lessons was 86 and that of the unplanned lessons was 52.

The observed mean difference between the planned and unplanned lessons average score was 35. A t-test analysis carried out to determine whether the observed difference was statistically significant.

Table 4: Results of t-test analysis of planned test and unplanned test scores of intern students

\begin{tabular}{|l|l|l|l|l|l|l|}
\hline Statistics & N & Mean & SD & Df & t-cal & $\begin{array}{l}\text { P. } \\
\text { value }\end{array}$ \\
\hline
\end{tabular}




\begin{tabular}{|l|l|l|l|l|l|l|}
\hline $\begin{array}{l}\text { Pre-test } \\
\text { Post-test }\end{array}$ & 8 & 34.50 & 5.57 & 7 & 19.37 & 0.00 \\
& & & & & & \\
\hline
\end{tabular}

The results $t(7)=19.37, \mathrm{p}<0.00$ shows that there is a statistically significant difference in the planned test and unplanned test scores of intern teachers with respect to their congruent feedback given.

Research Question 2: What influence does planning have on accuracy of cues by interns?

The purpose of this question was to assess the influence of planning on the accuracy of cues given in a lesson by interns. In answering this research question, the question on accuracy of cues on the QDITC instrument was used to collect data from the interns for analysis and is presented below.

\section{QDITC Accuracy of Cues from Interns}

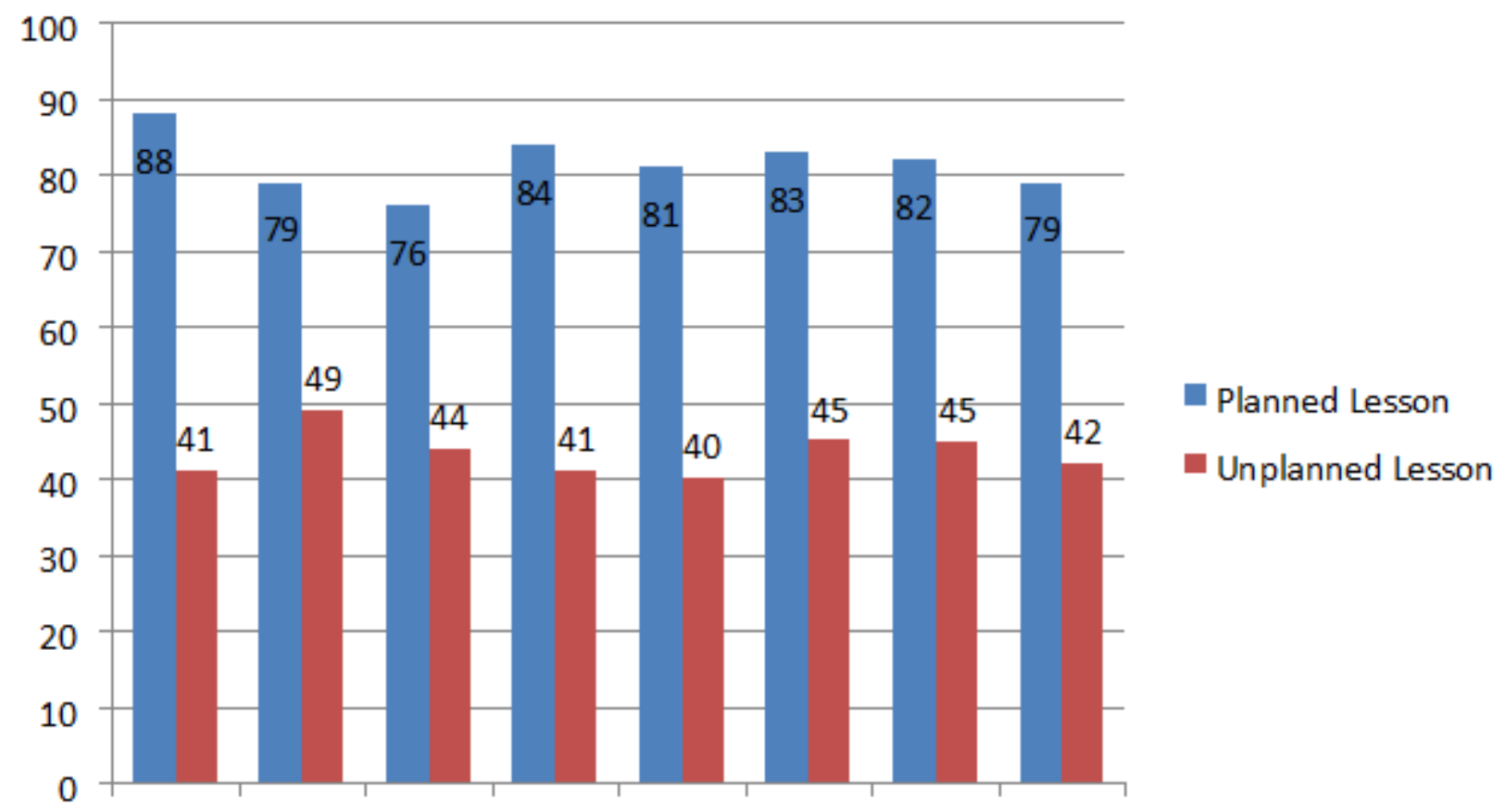

Intern 1Intern 2 Intern 3 Intern 4 Intern 5 Intern 6 Intern 7 Intern 8

Figure 2: QDITC Observation Report for Accuracy of cues

Figure 2 presents the individual scores of intern teachers on the QDITC instrument for planned and unplanned lessons with respect to the accuracy of cues given during lessons by interns. The table presents the average total percentage score for the observed lessons. From the data analyzed and presented there is clearly an observed difference between the planned lessons and the unplanned lessons with respect to accuracy of cues. The average percentage score for the planned lessons was 81.5 and that of the unplanned lessons was 43.4. The observed mean difference between the planned and unplanned lessons average score was 38.1. A t-test analysis carried out to determine whether the observed difference was statistically significant.

The results are presented in table 2 .

Table 2: Results of t-test analysis of planned test and unplanned test scores on accuracy of cues of intern students

\begin{tabular}{|c|l|l|l|l|l|l|}
\hline Statistics & N & Mean & SD & Df & t-cal & P. value \\
\hline
\end{tabular}




\begin{tabular}{|l|l|l|l|l|l|l|}
\hline $\begin{array}{l}\text { Pre-test } \\
\text { Post-test }\end{array}$ & 8 & 38.13 & 5.04 & 7 & 19.35 & 0.00 \\
& & & & & & \\
\hline
\end{tabular}

The results $t(7)=19.35, p<0.00$ shows that there is a statistically significant difference in the planned test and unplanned test scores of intern teachers with respect to their feedback given.

Research Question 3: How does planning affect demonstration by interns?

The purpose of this question was to assess the influence of planning on the demonstration given in a lesson by interns. In answering this research question, the question on accuracy of cues on the QDITC instrument was used to collect data from the interns for analysis and is presented below.

QDITC Demonstration in Lessons by Interns

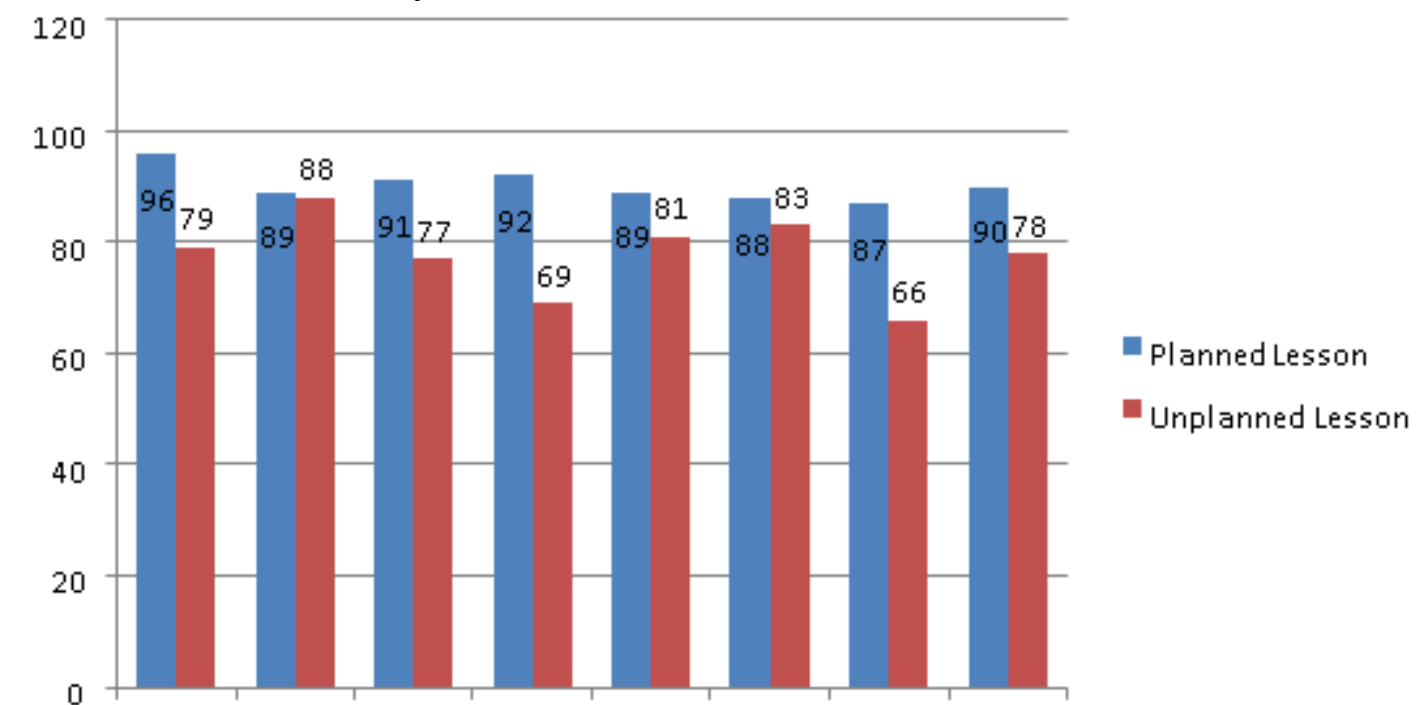

Intern 1 Intern 2 Intern 3 Intern 4 Intern 5 Intern 6 Intern 7 Intern 8

Figure 3: QDITC Demonstration in lessons by Interns

Figure 3 presents the individual average scores of intern teachers on the QDITC instrument for planned and unplanned lessons by interns during lessons. The table presents the average total percentage score for 4 observed lessons. From the data analysed and presented there is clearly an observed difference between the planned lessons and the unplanned lessons. The average percentage score for demonstration for the planned lessons was 89.6 and that of the unplanned lessons was 77.6. The observed mean difference between the planned and unplanned lessons average score was 12. A t-test analysis carried out to determine whether the observed difference was statistically significant. The results are presented in table 3 below.

Table 3: Results of t-test analysis of planned test and unplanned test scores on demonstrations of intern students

\begin{tabular}{|c|l|l|l|l|l|l|}
\hline Statistics & N & Mean & SD & Df & t-cal & P. value \\
\hline $\begin{array}{l}\text { Pre-test } \\
\text { Post-test }\end{array}$ & 8 & 12.63 & 7.69 & 7 & 4.64 & 0.002 \\
& & & & & & \\
\hline
\end{tabular}

The results $t(7)=4.64, p<0.002$ shows that there is a statistically significant difference in the planned test and unplanned test scores of intern teachers with respect to their feedback given.

Upon closer inspection, the demonstration data revealed that the intern teachers failed to provide any kind of demonstration in $50.0 \%$ of their task presentations in the unplanned lessons. In contrast, demonstrations were absent in only $17.8 \%$ of the intern teachers' task presentations in the planned lessons. 
Research Question 4: How does planning affect clarity of task?

The purpose of this question was to assess how planning of an instructional episode affects the clarity of the task given in a lesson by interns. In answering this research question, all the questions on the QDITC instrument (i.e. teacher position, learner attention, environment arranged, demonstration, accuracy of cues, appropriate number of cues and congruent feedback) were used to collect data from the interns for analysis and is presented below.

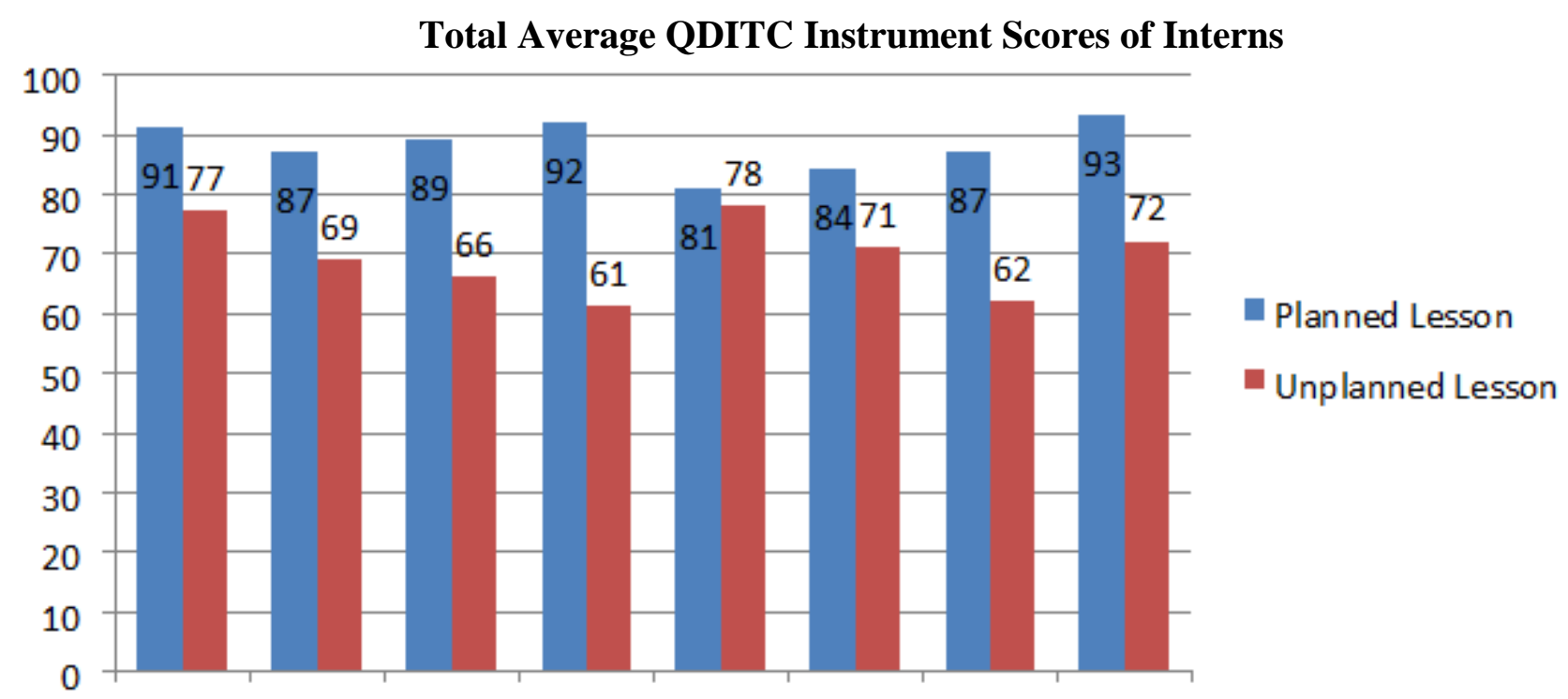

Intern 1 Intern 2 Intern 3 Intern 4 Intern 5 Intern 6 Intern 7 Intern 8

Figure 4: QDITC Clarity of Task in Lessons by Interns

Figure 4 presents the individual total average scores of intern teachers on the QDITC instrument for planned and unplanned lessons with respect to the clarity of lessons by interns. The table presents the average total percentage score for the observed lessons. From the data analysed and presented there is clearly an observed difference between the planned lessons and the unplanned lessons with respect to clarity of task. The average percentage score for the planned lessons was 88 and that of the unplanned lessons was 69.5. The observed mean difference between the planned and unplanned lessons average score was 18.5. A t-test analysis carried out to determine whether the observed difference was statistically significant. The results are presented in table 4 below.

Table 4: Results of t-test analysis of planned test and unplanned test scores on clarity of lesson by Teacher Interns

\begin{tabular}{|c|l|l|l|l|l|l|}
\hline Statistics & N & Mean & SD & Df & t-cal & P. value \\
\hline $\begin{array}{c}\text { Pre-test } \\
\text { Post-test }\end{array}$ & 8 & 18.5 & 8.59 & 7 & 6.10 & 0.000 \\
\hline
\end{tabular}

The results $t(7)=6.10, p<0.000$ shows that there is a statistically significant difference in the planned test and unplanned test scores of intern teachers with respect to clarity of the lesson which is made up of a combination of the total average scores of interns on the QDITC instrument.

\subsubsection{Testing of Hypothesis}

Based on the various literatures available, the following hypothesis was formulated for the study.

$\mathbf{H}_{\mathbf{0}} \mathbf{1}$ : There will be no significant difference between the instructional behaviours of the pre-service teachers across the two teaching conditions.

$\mathbf{H}_{1}$ 1: There will be a significant difference between the instructional behaviours of the pre-service teachers across the two teaching conditions.

Table 5: Average test scores on QDITC Instrument by Teacher Interns which shows effectiveness of instructional behaviour 


\begin{tabular}{|c|c|c|c|}
\hline Intern Number & Planned Lesson & Unplanned Lesson & Difference \\
\hline Intern 1 & 91 & 77 & 14 \\
\hline Intern 2 & 87 & 69 & 18 \\
\hline Intern 3 & 89 & 66 & 23 \\
\hline Intern 4 & 92 & 61 & 31 \\
\hline Intern 5 & 81 & 78 & 3 \\
\hline Intern 6 & 84 & 62 & 25 \\
\hline Intern 7 & 87 & 72 & 21 \\
\hline Intern 8 & 93 & & 13 \\
\hline
\end{tabular}

Average 88

69.5

18.5

From table 5 above there is an observed difference in the instructional behaviour of the interns on the planned and unplanned lessons with the interns scoring higher percentage scores on the planned lessons than on the unplanned lessons. A t -test analysis carried out to determine whether the observed difference was statistically significant.

From the table above it can be seen that there is a statistically significant difference in the instructional behaviour of the pre-service teachers across the two teaching conditions with the teachers on the planned teaching condition scoring better than those in the unplanned teaching condition. Thus the researcher can reject the null hypothesis and accept the alternate hypothesis $\mathbf{H}_{\mathbf{1}} \mathbf{1}$ which states that "There will be a significant difference between the instructional behaviours of the pre-service teachers across the two teaching conditions".

\subsubsection{Qualitative Data Analysis}

From the focus group interview conducted with the interns, they passed the following comments with regards to their observed difference between instructional behaviours in planned and unplanned teaching conditions.

One intern stated that:

"I have realized that when I take time to plan ahead of my class I am able to deliver better. I really do have a fulfilled session and at the end of the day I am happy and can see that my students also gain a lot from those sessions. Unlike my unplanned class sessions where even though I am able to deliver, I know that it is not to the best of my ability."

Another intern also commented that:

"My planned class sessions are the best I have for my students as I can plan ahead of time for the most common scenarios, issues that may occur and questions that they may ask. I am able to give them the necessary feedback, and at the end of the day from my observation and remarks from the students, the lessons are clear"

Others comments by the interns were:

"Undoubtedly the planned class session are better than the unplanned. It's just like every other thing in life, if you plan you can manage things better. But when you do not plan you are taken by unforeseen events or circumstances."

"We were taught about lesson planning in school but right here on internship I have seen it manifest before my eyes. I used to feel that I knew it all and could just walk into a class and teach without prior preparation and planning. On those days I do not plan I can vividly see that the class session and instruction does not flow. However on those days that I actually take 
time to plan, I can see a difference and I can tell that my students have learnt well and I have also delivered my best."

"There is the need for us students to be educated on the importance of planning in instruction delivery and even let people share their practical experiences. This will go a long way to help we teachers plan and give off our best and ensure that students do indeed get maximum benefits from their class sessions."

\subsection{Discussion on Research Questions}

\subsubsection{Findings on Research Question1}

The finding for research question one revealed that there was indeed an observed difference between planned and unplanned lessons with regards to the provision of feedback of interns. This observed difference was statistically significant with interns providing a higher number of congruent feedbacks in the planned sessions than in the unplanned lesson sessions.

The findings of the current study are in line with that of a study released at the recent Campus Technology 2010 conference, Waypoint Outcomes (2010) found that students are more engaged and learn more effectively when they receive consistent feedback from their professors. They also found that timeliness, clarity and personalization are the most important qualities in instructor comments. It is a wellknown fact that every student knows the difference between getting a paperback stamped with a letter grade and getting it back covered with thoughtful feedback. One may quantify your progress, but the other actually tells you what you did right - and how to improve. Acknowledging the important role that feedback plays in 'quality teaching and student learning,' education technology company Waypoint Outcomes commissioned a study exploring student perceptions of professor feedback. In June

2010, Waypoint conducted an online survey of undergraduates from across the U.S.

The company presented the results of the study at the recent Campus Technology 2010: Advancing Higher Education through Technology conference, alongside their new software for grading and giving student feedback. Out of 473 respondents to the survey, $85 \%$ study on-campus, $2 \%$ just take courses online and $13 \%$ take a combination of online and on-campus classes. As the number of students taking online classes grows, the question of engaging these students has become especially important. Lacking face to face interaction with either their professors or their classmates, online students have a higher need for other forms of interactive engagement with the material. Solutions have included online message boards, interactive websites and even video conferencing, but the Waypoint study reminds instructors of the importance of the basics: Giving high quality feedback on coursework. Of all the students surveyed, $98.8 \%$ agreed or strongly agreed that 'timely, personalized feedback' makes them more effective learners. One respondent commented, 'When I receive thorough feedback, I can better know what is expected of me and will perform better in the future.' Another added, 'It makes you feel like the professor actually cares about your work and that you are doing homework. It makes me try harder.'

The issue of actively engaging students with their coursework is a key one. Studies at community colleges, which tend to have a high rate of student attrition, have found that having clear academic expectations and forging early connections with professors are crucial for keeping students in school. Another study focused on 4-year colleges and universities found that the most predictive factor of student persistence is how students feel about their institutions in the first eight weeks of school - an attitude that's shaped in large part by the quality of their interactions with professors. As student comments on the Waypoint study emphasize, students who get feedback for their work are motivated to perform better - and, in turn, are more likely to stay in school.

In spite of the importance of feedback, many faculty are falling down on the job. The Waypoint survey found that students aren't happy with the quality of the feedback they're receiving. Only $15.4 \%$ of respondents 'strongly agreed' that they're satisfied with the feedback they receive from their professors. An equal number disagreed or strongly disagreed.

So what are the qualities that are missing? Timeliness and personalization. One student commented, 'It's difficult to assess how well you are learning the material when it takes so long for professors to grade assignments.' Another noted, 'A lot of the time I do not feel that I receive adequate personalized feedback. I realize professors keep busy schedules with multiple courses, hundreds of students, and research, but I believe adult education should be centred on individual responsiveness.' 
Of those students who did indicate being satisfied with their course feedback, $98.6 \%$ said that their professors returned their work within one week. For students who are trying to keep up with heavy course loads and frequent assignments, getting feedback on time is crucial for applying it to future work. One student notes, 'By getting feedback quickly, I feel that I can better complete upcoming assignments. When rubrics or expectations are not given I feel more pressure about assignments and I am unsure what is necessary to adequately complete the assignment.' Using clearly defined rubrics to set expectations and give student feedback is another important quality. Of those satisfied with the feedback they receive, $86.3 \%$ said that their instructors frequently used such rubrics. Although the emphasis on defined rubrics supports Waypoint's promotion of their software, it's the issue of clarity that emerges as key among student comments. Clearly defined expectations and specific, personalized feedback on how individuals are meeting those expectations set students up for success: 'Personalized feedback not only helps me do better in the class, but it helps me understand exactly how my teachers want me to interpret the assignments.'

\subsubsection{Findings on Research Question 2}

The findings for research question two revealed that there was indeed an observed difference between planned and unplanned lessons with regards to the accuracy of cues provided by interns. This observed difference was statistically significant with intern providing better feedback in the planned sessions than in the unplanned lesson sessions.

A teacher's overall instructional effectiveness depends heavily on how that teacher uses instructional cues. A cue consists of a word, phrase, or sentence that describes a particular aspect of a concept or skill. While cues most often focus on motor skill development in physical education, they may also target fitness, strategy, character development, or any other aspect of lessons teachers deem appropriate. A growing body of research suggests that cues enhance learning by improving student attention, comprehension, and retention.

Cues enhance the attention or focus of learners by restricting what they need to think about. Since learner's capacity for attention is limited, it is important to deplete the capacity with relevant, rather than irrelevant (or perhaps, less relevant) stimuli. Consequently, cues play an important role in directing student's attention toward the most critical information, and away from less critical information. As Buchanan and Briggs (1998) put it, "While having more than one cue for the same movement is useful, be careful not to confuse a student by bombarding him or her with an endless variety of hints" (p.17).

In addition to helping students attend to ideas in a lesson, cues help students comprehend ideas. Developmental cues result from focusing on (a) process elements before product elements, and (b) basic process elements before advanced process elements. Focusing too much on product elements, such as distance and accuracy, directs learner focus away from understanding how to produce a given movement. Although emphasizing advanced process elements retains proper focus, ideas are too difficult to grasp if basic elements are not understood first. After communicating cues clearly, teachers are encouraged to incorporate the same ideas as part of the feedback process (Landin, 1994). In this way carefully chosen cues help teachers target their feedback throughout a lesson and unit.

While understanding ideas is important, it would serve little purpose if students did not retain the information for future application. Retention is especially enhanced when cues connect new ideas to previously learned ideas in some way (Magill, 1993). In addition, retention is related to attention and comprehension chronologically: To the degree that learners (a) attend to cues, and (b) comprehend cues, they are more likely to (c) retain the information for future use. Conversely, if students are not attentive, and do not understand cues, they are ill-prepared to apply them in the future. Certainly, one of the aims of education is to foster desire and ability for students to learn independently.

Although instructional cues generally help students attend to tasks, comprehend ideas, and retain ideas, the effectiveness of a cue depends on its particular composition. From a potentially long list of criteria for effective cues, four are described below. Cues need to focus on the most central or relevant information. With limited class time, teachers need to "get the most bang for their buck." What makes a particular cue central or relevant? It has to do with how important that information is to achieving success. Some cues are important because they target proximal aspects of movement. If a child does not know what direction to face his trunk while batting, telling him to shorten his swing has little value. It is less proximal (or more distal). Less proximal cues become more necessary as movement is refined because proximal aspects are more ingrained or automatic (Rink, 1993). The notion of importance or centrality applies to all 
areas of instruction, not just skill development. For instance, it is more important to understand that volleyball strategy involves a bump-set-spike, than to understand the benefits of spiking the ball down the line. These examples reveal that the criterion of centrality is closely related to the developmental nature of cues.

A second criterion for effective cues is degree of accuracy. A cue can be relevant, yet be inaccurate or incorrect. While teachers may agree that how to grip a tennis racket ranks high in importance, comparing the grip to holding a pencil is terribly inaccurate. As with centrality, accuracy of cues concerns more than skill development. Although eating a balanced diet would be relevant to teaching fitness principles, teaching students that the primary energy source is fats would be inaccurate.

Brevity has benefit for the teacher and student. From the teacher's standpoint, preparing cues in a concise manner makes it easier to organize relationships between ideas, and to remember cues when it's actually time to use them. From the student's standpoint, the concise cue is easier to remember as well. It is much easier for a student to remember to "shake hands with the racket", than to "grip the racket with the top of the racket midway between the thumb and index finger."

The creativity of a cue contributes to learning in significant ways, yet is less important than the other criteria. As with brevity, a creative cue is more likely remembered than an uncreative cue. Ideas may be expressed creatively through several types of cues, including, but not limited to acronyms, alliteration, rhymes, slogans and similes or word pictures. Each type of cue may be instrumental in helping learners connect new learning to old learning. Examples of each type of cue are provided in the left hand margin.

Physical educators need to guard against achieving one cue criterion at the expense of another. For example, using alliteration creatively is helpful only to the degree it is also correct (and concise). In this vein, telling students that "practice makes perfect" does them a disservice. Instructional cues may be expressed in three general ways: verbally, visually and kinesthetically. The content of a cue determines the teacher's options. Although students could form the letters with their bodies, taking the time is not warranted because no reference is made to movement mechanics. By contrast, "sitting down in a chair" at the end of a spiking approach may be expressed in all three ways effectively. Teachers are encouraged to vary how cues are expressed, recognizing that students may respond better to one cue than another.

Verbal cues are used most widely by physical educators because they represent the most common way to communicate, and because the largest quantity of information may be expressed verbally. In addition, verbal information is not easily misinterpreted if expressed clearly. A disadvantage of verbal cues is that, while teachers rely on one-way verbal exchanges as their primary means of teaching, a small percentage of learners rely on predominantly auditory information.

Visual and kinesthetic cues are helpful to all learners for the sake of variety, and to visual and kinesthetic learners, respectively, in particular. In addition, visual and kinesthetic cues are especially appropriate when visual cues have limited value. An obvious situation that renders verbal cues less valuable is any time a language barrier exists. With increasing students of other cultures in physical education classes, it is helpful to utilize visual demonstrations or physical manipulation to convey movement ideas. Naturally, manipulation needs to fall within the teacher's and student's comfort level for physical touch. Another situation in which verbal cues are less valuable is in teaching technical movements with complicated directions. For this reason, visual and kinesthetic cues are used widely in the teaching of gymnastics and diving. It is marginally helpful to tell a student to align the hips over the shoulders in a handstand, if the student doesn't receive help to see and feel what that is like.

A further advantage of visual cues is when the teacher is too far away to use verbal cues. If a class is practicing throw-ins on a soccer field, a teacher could remind selected students to drag their rear foot by modeling the movement from 20 or 30 yards away. Of course, the usual context for understanding the visual cue is created earlier with a verbal cue.

\subsubsection{Findings on Research Question 3}

The finding for research question three revealed that there was indeed an observed difference between planned and unplanned lessons with regards to demonstration in class by interns. This observed difference was statistically significant with intern providing better demonstration in the planned sessions than in the unplanned lesson sessions.

Demonstration is an essential teaching approach in supporting the learning of a skill at any level or grade and is the most supportive of all the teaching approaches (Cambourne 1988; Mooney 1990). The 
other teaching approaches — shared, guided, and independent - are all used to support student learning, but each approach respectively offers less teacher guidance than the one before it. As the students gain more knowledge about a particular skill, they need less support and the approach should change. Demonstration is typically used to introduce a new skill to a whole group, but it can and should apply to individuals or a small group whenever more support is needed for their learning.

Demonstration involves showing by reason or proof, explaining or making clear by use of examples or experiments. Put more simply, demonstration means 'to clearly show'. In teaching through demonstration, students are set up to potentially conceptualize class material more effectively as shown in a study which specifically focuses on chemistry demonstrations presented by teachers (McKee, Williams \& Ruebush, 2007). Demonstrations often occur when students have a hard time connecting theories to actual practice or when students are unable to understand application of theories.

Teachers not only demonstrate specific learning concepts within the classroom, they can also participate in demonstration classrooms to help improve their own teaching strategies, which may or may not be demonstrative in nature. Although the literature is limited, studies show that the effects of demonstration classroom teachers includes a change of perspective in relating to students, more reflection in the teachers' own classroom strategies, and more personal responsibility for student learning (Bruce, Ross, Flynn \& McPherson, 2009).

Demonstration, or clearly showing (a gamut that ranges from mere pointing to more sophisticated strategies such as chemical reactions), can possibly be used in portraying ideas such as defining words. At first, simple observation and communication through pointing to an object, area, or place, like the sun, moon, or a large mountain top, occurs. Then basic definitions of words emerge. These definitions allow humans to communicate, interact, plan, and co-ordinate in ways that help us to build cities, large buildings, technology, gain knowledge and to successfully communicate with computers. Further, basic concepts centred on time, space, and mathematics are first required to demonstrate and teach probable theories that accurately describe universal phenomenon such as nature, planets, species, and the world around us.

The history of phenomenon demonstrating concepts, which lead to specific definitions, goes back to the careful observations of ancient Greek philosophers and natural philosophy. Socrates, Plato, and Aristotle attempted to carefully define words that included natural phenomena and objects. The modern scientific method often uses demonstrations that carefully describe certain processes and parts of nature in great detail. In science, often one demonstrates how an experiment is done and shows this to others. People can also communicate values and ideas through demonstrations. This is often done in plays, movies, and film. Pictures without words can show or demonstrate various types of actions and consequences.

\subsubsection{Findings on Research Question 4}

The data analysis for research question four showed that there was a statistically significant difference in the planned test and unplanned test scores of intern teachers with respect to clarity of task which is made up of a combination of the total average scores of interns on the QDITC instrument. Pre-task, task, and post-task presentation behaviours show the teacher's ability to clearly communicate accurate qualitative motor-skill information to attentive learners such that the learners can proceed to work in a focused manner on tasks. The three pre-task dimensions (teacher position, learner attention, and arrangement) are included because it is possible for a teacher to clearly communicate accurate qualitative motor-skill information to learners, yet have few learners' exhibit appropriate behaviour in task performance. Novice teachers are so intent on getting through task presentations that they often neglect to focus learner attention and to arrange the task environment before informing the learners about the task. Capturing learner attention and arranging the task environment prior to task presentation seems critical to learner understanding and, in turn, to learner response appropriateness. One of the focal points of the teacher subjects' first formal experience was to verify learner attention before providing instruction.

The five task presentation dimensions reflect the teacher's ability to identify and clearly communicate accurate qualitative task cues to the learners (Rink \&Werner, 1989). There is some evidence to suggest that teachers who clearly communicate qualitative aspects of skill movement tend to be more effective than teachers who do not, as reflected by learner performance (Gusthart \& Sprigings, 1989; Rink \& Werner, 1989; Werner \& Rink, 1989).

The QDITC data seem to suggest a relationship between task and post-task presentation behaviours. When the pre-service teachers presented demonstrations and provided qualitative skill cues during task 
presentations, they were likely to offer specific, congruent feedback during post-task presentations. In the planned lessons, the pre-service teachers presented partial or complete demonstrations and provided qualitative skill cues in more than $80 \%$ of their task presentations and specific, congruent feedback in more than $75 \%$ of their post-task presentations.

In summary, in the unplanned lessons the pre-service teachers presented partial or complete demonstrations and provided qualitative skill cues in less than $50 \%$ of their task presentations and specific, congruent feedback in less than $40 \%$ of their post-task presentations. Presenting the learners with the model for skill performance in combination with specific skill-cue information seemed to influence the pre-service teachers' ability to offer specific, congruent feedback during activity time. This is an important finding in light of Werner and Rink's (1989) description of effective instructional characteristics, which reported that greater performance gains were recorded by learners when teachers offered specific feedback that, matched the cues given to the learner as a focus.

\section{Conclusions}

The purpose of this study was to assess the influence of planning on the instructional behaviours of a group of student-intern Physical Education major students who were on their internship programme. The descriptive statistical analysis revealed that there was a statistically significant difference between interns in their planned and unplanned lessons with respect to feedback, cues, demonstration and clarity of task. In light of these findings, it seems important that prospective teachers be given ample opportunity to plan, implement, and evaluate instruction on a regular basis beginning early in their pre-service training. In addition, it seems critical that components of planning and teaching, because of their existing link, be introduced and developed (taught and practiced) in combination. Given the limited data base, there is a need for continued research to further examine the effect planning has on the other aspects of instructional behaviours of teachers who are learning to teach.

\subsection{Implications}

As the current studies has established, there is a statistically significant difference between planned and unplanned lessons presented by students interns with interns performing better when the lesson was planned than when it was unplanned with respect to feedback, accuracy of cues, demonstration and clarity of task. These findings will go a long way to improve the quality of lessons presented by interns who would subsequently become teachers in ensuring that lessons are utilized to the fullest and ensure that students are well taught and get the best out of the lessons. This will ensure that the students will in turn give off their best in their various roles they play in physical education lessons in the nation at large.

It is also believed that this study has provided an insight into assessing the influence of planning on selected instructional behaviours of physical education student-interns. However, there could be other factors that need to be identified or evaluated. Hence, it is the view of the researcher that further research needs to be carried out in the area and expanded to include other regions.

\subsection{Recommendations}

Based on the findings from the study, the researcher would like to make the following recommendations:

- Ample opportunities to plan, implement, and evaluate instruction on a regular basis beginning early in their pre-service training. In addition, it seem critical that components of planning and teaching, because of their existing link, be introduced and developed (taught and practiced) in combination.

- Given the limited data base, there is a need for continued research to further examine the effect planning has on the instructional behaviours of teachers who are learning to teach.

- In addition, workshops and seminars should be organized for teachers and P.E. instructors on the effects of planning on instructional behaviour.

\section{References}

[1] Bruce, C., Ross, J., Flynn, T., \& McPherson, R.(2009).Lesson study and demonstration classrooms: Examining the effects of soft models of teacher professional development. Retrieved from Munich Personal RePEc Archive website: http://mpra.ub.uni-muenchen.de/31963/http://mpra.ub.unimuenchen.de/31963/ 
[2] Byra, M. (1992). Measuring qualitative aspects of teaching in physical education. Journal of Physical Education, Recreation, and Dance, 03), 83-89.

[3] Byra, M., \& Sherman, M. (1993). Preactive and Interactive decision-making Tendencies of Less and More Experienced Pre-service Teachers. Research Quarterly for Exercise and Sport, 64 (1), 46-55.

[4] Cambourne, B. (1988). The whole story: Natural learning and the acquisition of literacy in the classroom. Aukland, New Zealand: Ashton Scholastic.

[5] Gusthart, L, \& Springings, E. (1989). Student learning as a measure of teacher effectiveness in physical education. Journal of Teaching in Physical Education (4), 298-311.

[6] Landin, D. (1994). The role of verbal cues in skill learning. Quest, 46, 299-313.

[7] Magill, R. (1993). Motor learning: Concepts and applications (4th ed.). Dubuque, IA:Brown.

[8] McKee, D. F., Williams, J. R., Ruebers, D. M.. (2007).Evaluating value-added models for

[9] teacher accountability. Santa Monica, CA:RAND Corporation. Retrieved February 19, 2009, fromhttp://www.rand.org/pubs/monographs/2004/RAND_MG158.pdfhttp://www.rand.org/pubs/mo nographs/2004/RAND_MG158.pdf

[10] Mooney, M. E. (1990). Reading to, with, and by children. Katonah, NY: Richard C.Owen.

[11] Rink, J. (1993). Teaching physical education for learning. St. Louis, MO: Mosby.

[12] Rink, J., \& Werner, P. (1989). Qualitative measures of teaching performance scale (QMTPS). In P. Darst, D. Zakrajsek, \&V. Mancini (Eds.), Analyzing physical education and sport instruction (pp. 269-275). Champaign, IL: Human Kinetics.

[13] Sherman, M. A. (1979). A study of expert and novice gymnastics teachers. Paper presented at the annual meeting of the PSAHPERD (pp. 19-34). Pittsburgh: P.A publishers.

[14] Waypoint, O. (2010). Exploring student perceptions of professor feedback. Advancing Higher Education Through Technology. Philadelphia: PR Newswire.

[15] Werner, P., \& Rink, J. (1989). Case studies of teacher effectiveness in second grade physical education. Journal of Teaching in Physical Education, 11(4),280297.

[16] Yinger, R.J. (1979). Routines in teacher planning. Theory into Practice, 17, 163=69. Yinger, 